\title{
La peste Antonina: una peste global en el siglo II d.C
}

\author{
Andrés Sáez
}

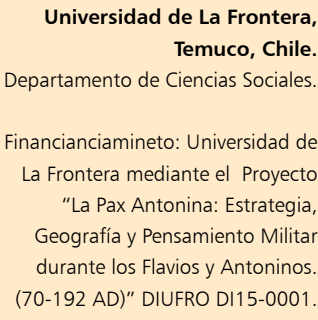

Recibido: 24 de noviembre de 2015

Correspondencia a: Andrés Sáez Geoffroy andres.saez@ufrontera.c

\section{Introducción}

$\mathrm{D}$ e acuerdo a los historiadores, el Imperio Romano experimentaba en el siglo II d.C su época de oro, con un gobierno benigno y una unidad cultural que abarcaba toda la cuenca del Mediterráneo ${ }^{1}$. No obstante aquello, entre 165 al 180 d.C estalló una peste que afectó a todo el Imperio Romano cuyas proporciones geográficas y humanas nunca antes habían sido vistas en la historia de la humanidad ${ }^{2}$. La llamada peste Antonina constituye una de las coyunturas médicas más relevantes para el devenir del mundo clásico y occidental, quizá al mismo nivel de la peste negra en el siglo XIV o la gripe española en 1918.

El impacto de la crisis puede ser catalogado sin duda como global desde un punto de vista geográfico. En el siglo II d.C el Imperio Romano tenía como límites en el norte a Britania, el Rhin y el Danubio, al oriente el norte de Mesopotamia, mientras que en África del norte, la cuarta catarata del Nilo en Egipto y el desierto del Sahara constituían las fronteras de un Imperio cuya población se estima cercana a los 50 millones de habitantes. El Imperio ocupaba gran parte de lo que actualmente es Inglaterra y Alemania, toda España y Portugal, Italia, Suiza, parte de Eslovaquia, República Checa, Croacia, Serbia, Montenegro, Albania, Bulgaria, Rumania, Grecia, Turquía, Siria, Armenia, Israel, Palestina, Egipto, Libia, Marruecos y Argelia (Figura 1).

Dentro de aquellos límites, en el siglo II d.C., se había consolidado el proceso de romanización por el cual los pueblos conquistados en siglos anteriores habían adquirido los principales hábitos culturales de los conquistadores romanos ${ }^{3}$. La vida en ciudades, el uso del latín o griego como lenguas comunes y oficiales, una extensa red vial de comunicaciones entre las diferentes provincias, el uso de las mismas tecnologías (baños, acueductos, arquitectura, etc.) entre otros tantos factores, llevaron a que las personas que componían el imperio se sintieran parte en mayor o menor grado de una communis patria que vivía un período de paz, estabilidad y tranquilidad, lo que se ha denominado pax romana ${ }^{3}$.

Se configuró así en el siglo II la idea de que el orbis terrarum, es decir, el globo terrestre era lo mismo que el orbis romanus, vale decir que la tierra civilizada era el Imperio Romano y todo lo que se encontrara dentro de sus límites; conformando una especie de mundo propio que ocupaba sin duda la mejor parte del planeta. De esta forma, cuando en el título nos referimos a una crisis global es en clara referencia a que el mundo romano para el siglo II se encontraba unificado por diferentes factores, asemejándose en cierto sentido a la globalización actual como lo ha señalado acertadamente Alejandro Bancalari ${ }^{4}$.

Será en dicho contexto de unidad geográfica y cultural que estallará en el año 165 una pandemia de fuertes proporciones que habría de alterar el desarrollo histórico del Imperio Romano.

\section{Orígenes, difusión y características de la peste Antonina}

Las fuentes que nos informan sobre la plaga son bastante fragmentarias, sobre todo las relativas a la etiología y al diagnóstico de la peste. Sin duda la fuente más relevante la constituye Galeno, quien mejoró las bases de la medicina hipocrática y cuya influencia se extenderá por todo el mundo árabe y medieval. La importancia de Galeno está dada porque presenció la epidemia al 
trabajar directamente con el emperador Marco Aurelio y el ejército, en el momento en que la peste alcanzaba su punto álgido en las guerras marcománicas ${ }^{5}$ (Figura 2).

Siempre de acuerdo a las fuentes, disponemos de dos posibles lugares de origen de la plaga. La versión más difundida sitúa su origen en una de las expediciones de la campaña oriental del año 165 y específicamente en la ciudad de Seleucia (actual Irak), donde un soldado habría profanado el templo de Apolo de aquella urbe al abrir un cofre, del cual habría salido un vaho pestilente. Dicha versión ha sido difundida por la Historia Augusta ${ }^{6}$ y Amiano Marcelino, ambos del siglo IV. Otra versión, hallada en un fragmento de Calpurniano Crepereyo, cuya obra está casi del todo perdida, señala que la peste se originó en Egipto siendo propagada desde allí en la medida que el grano egipcio fue llegando a diferentes lugares del Imperio ${ }^{7}$. En Roma se contó la mayor morbilidad por la concentración de población existente, se cree cercana a un millón de habitantes ${ }^{8}$.

Más allá del lugar exacto del origen, es posible señalar que la peste se originó en oriente y desde allí se difundió ampliamente mediante los diferentes mecanismos de interconexión imperial, sea la gran red viaria terrestre o naval, o bien del comercio a gran escala a lo largo de todo el Imperio. Sin duda el gran movimiento demográfico, sobre todo de soldados que volvían de la campaña oriental, parece haber sido el principal factor propagador. De acuerdo a la Historia Augusta, el retorno de Vero y el ejército oriental "tuvo la fatalidad, según parece, de llevar consigo la peste a todas las provincias por donde pasó hasta que llegó a Roma" " . Hablamos de un cuerpo militar compuesto como mínimo por unas cien mil personas, carentes de servicios higiénicos adecuados, por lo que los riesgos desde el punto de vista epidémico eran más que obvios.

De esta forma la plaga "llena de enfermedad y muerte a todo el territorio situado entre la tierra de los persas, el Rhin y las Galias" ${ }^{6}$ o sea todo el Imperio, rememoraba Amiano Marcelino (23.6.24). La lógica de unificación del territorio romano contribuyó a una rápida difusión de la enfermedad, tal cual como pasaría hoy en día con una crisis similar a gran escala.

Los síntomas de la enfermedad fueron descritos por Galeno y han generado un debate interesante en cuanto a la determinación con exactitud de qué tipo de padecimiento se trataría. Los síntomas de la enfermedad según Galeno 9 eran los siguientes: "exantemas de color negro o violáceo oscuro que después de un par de días se secan $y$ desprenden del cuerpo, pústulas ulcerosas en todo el cuerpo, diarrea, fiebre y sentimiento de calentamiento interno por parte de los afectados, en algunos casos se presenta sangre en las deposiciones del infectado, pérdida de la voz y tos con sangre debido a llagas que aparecen en la cara y sectores cercanos, entre el noveno día de la aparición de los exantemas y el décimo segundo, la enfermedad se manifiesta con mayor violencia y es donde se produce la mayor tasa de mortalidad".

Los investigadores han descartado la peste bubónica y la fiebre tifoidea ya que en las fuentes no se aprecia la existencia de bubones en las axilas y ganglios, a su vez el sarpullido, según Galeno, se presenta siempre en la etapa de las pústulas, cuestión presente en la viruela

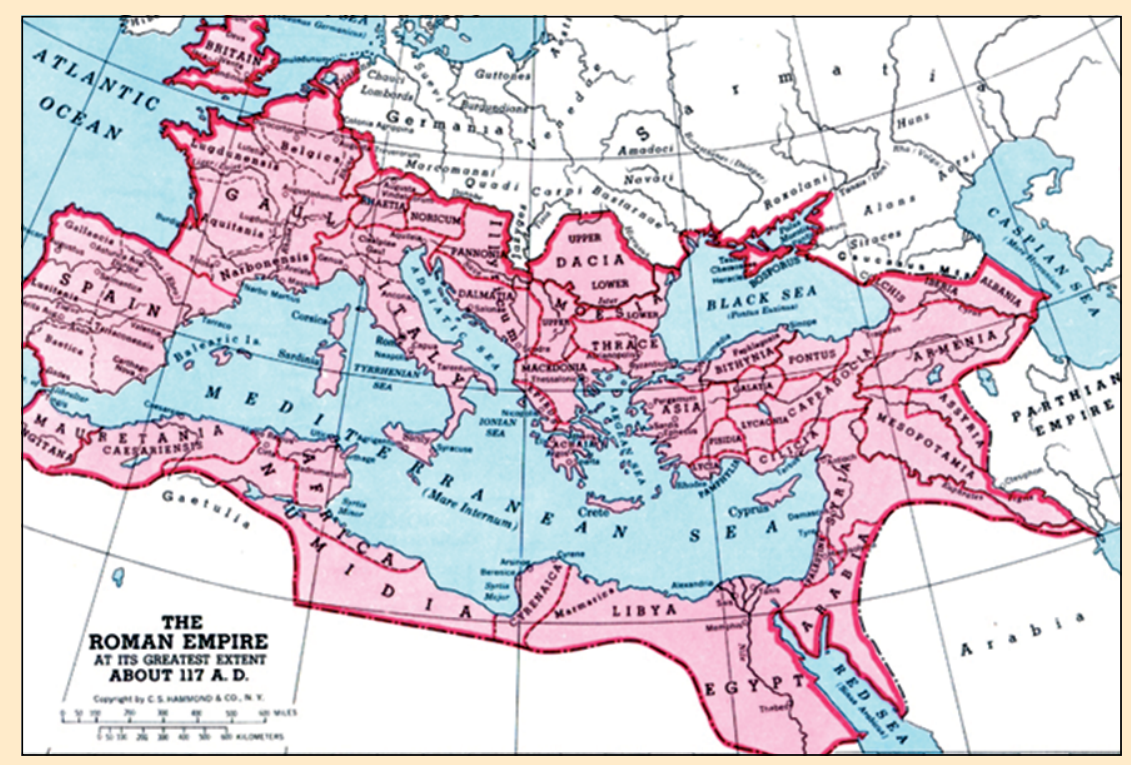

Figura 1. El Imperio Romano en el siglo II d.C. Fuente: http://coursesa.matrix.msu.edu/ fisher/hst372/ readings/maps/RomanEmpire.JPG.

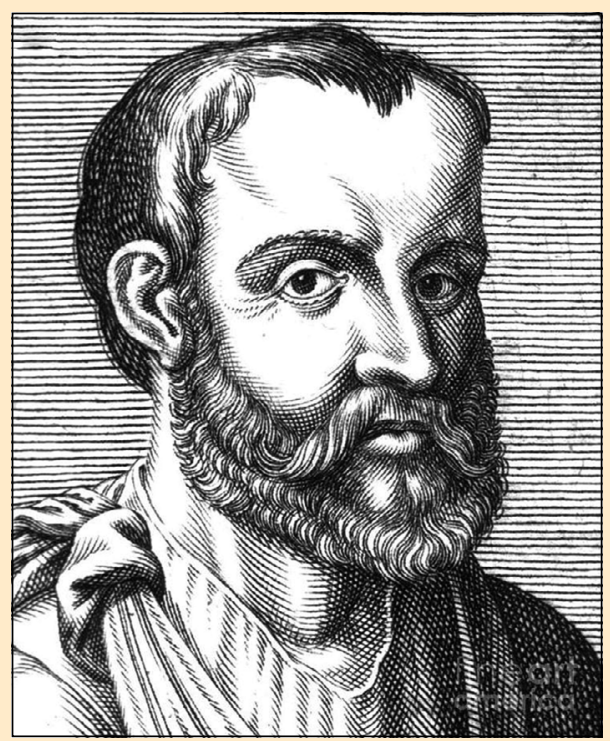

Figura 2. Galeno. Fuente: http://images.fineartamerica.com/ images-medium-large/5-galen-greek-physician-and-philosopherscience-source.jpg. 
y no en otras enfermedades; dicho síntoma unido a los otros descritos permitieron afirmar a Littman y Cunha que se trataría de una viruela de tipo hemorrágica ${ }^{10,11}$. Su difusión sin duda se debió al hecho de que se trataba de un gran conjunto humano desplazándose en sentido oriente-occidente que explicaría el alto grado de contagio y propagación geográfica de la enfermedad.

\section{Los efectos de la peste en la sociedad romana del siglo II d.C.}

Se ha estimado que en promedio la peste Antonina debió tener una mortalidad de 7 a $10 \%$ de la población imperial, es decir, habrían muerto en el Imperio Romano entre unos tres millones y medio a cinco millones de personas producto de la epidemia. Las cifras para el caso del ejército y las ciudades se estiman ligeramente superiores en torno a $13-15 \%$ de mortalidad debido a los grados de concentración y la falta de sistemas higiénicos como los actuales que hubieran ayudado a prevenir la difusión y a controlar la plaga ${ }^{11}$.

De esta forma el impacto mental, social, económico y militar de la crisis fueron importantes en el devenir del Imperio Romano sobre todo pensando que no se contaban con los medios ni el conocimiento tecnológico como los actuales como para superarla y explicarla a cabalidad. De inmediato los cadáveres fueron vistos como agentes de transmisión y no faltó quienes vieran la pandemia como un castigo de los dioses por alejarse de sus designios.

La imagen más terrible de la peste la ofrece la vida de Marco Aurelio inserta en la Historia Augusta, la que señala que en plena campaña contra los marcomanos

Figura 3. El emperador Marco Aurelio. Estatua en el Museo Capitolino. Fotografía del autor. en el Danubio "surgió una epidemia tan grande que los cadáveres se transportaron en distintos vehiculos y carruajes. Los Antoninos promulgaron entonces leyes severísimas respecto a la inhumación y a las sepulturas, pues prohibieron que nadie las construyera a su gusto, reglamentación que se observa todavía hoy. Por cierto, dicha epidemia acabó con muchas miles de personas, muchas de ellas de entre los primeros ciudadanos" ". Las leyes aún se conservan en el Digesto y tratan específicamente sobre las penas para las personas que ocupaban nichos vacíos para enterrar sus deudos y los lugares donde hacerlo, pero las que más impacto tuvieron son las referentes a que el traslado de cadáveres debía hacerse con permiso de la autoridad local competente y nunca pasando por en medio de las ciudades para evitar todo posible contagio ${ }^{12}$.

No hubo clase social que se librara, lo que demuestra la virulencia de la pandemia, sobre todo considerando que las clases altas tenían mejores condiciones sanitarias y alimentarias. La plaga afectó a todos por igual, incluso el mismísimo emperador Marco Aurelio falleció a causa de la viruela en 180, no sin antes expresar en sus últimas palabras su preocupación por los pobres afectados por la pestilencia. Roma, la ciudad eterna, sufrió el embate con mayor dureza por la cantidad de población aglomerada y hacinada. Muchas actividades económicas tuvieron que paralizarse al nivel que se fijaron las paces con los enemigos de Roma, en las cuales se estipulaba su ingreso para establecerse como colonos para trabajar la tierra y ser soldados. En otros casos como en Hispania, Morris Silver sostiene que la plaga terminó con la labor minera ya que subió el valor de los esclavos y la mano de obra haciendo las ganancias menos rentables que antaño ${ }^{13}$ (Figura 3 ).

El ejército también se resintió bastante, el reclutamiento se hizo forzoso ingresando esclavos, delincuentes, forajidos y gladiadores al ejército. Se llegó a tal punto que Roma tuvo que contratar mercenarios e inclusive utilizar fuerzas de los bárbaros aliados. Marco Aurelio “ordenó preparar para la milicia a esclavos a los que como a los «volones» dio el nombre de «voluntarios». Equipó con armas también a los gladiadores a los que llamó «complacientes». Enroló como soldados a ladrones de la Dalmacia y de la Dardania. Armó también a los «diogmitas» y compró tropas auxiliares a los germanos ${ }^{6}$. La situación debió haber sido extremadamente crítica, lo que claramente generó un clima de inestabilidad social.

La reacción inmediata de los romanos fue la de invocar a los dioses para superar la peste, recurriendo a ritos tradicionales inclusive caídos en desuso. Marco Aurelio, dado que entonces arreciaba aún la epidemia, restableció con gran escrupulosidad el culto a los dioses ${ }^{15}$. La culpa de la peste fue echada inclusive a los cristianos quienes aumentaban cada en día en número y eran vistos como traidores al estado romano, y con ello al culto imperial, 
siendo atacados y perseguidos por ello. La peste generó un contexto en el que surgían charlatanes e impostores vendiendo amuletos y otros animando a la plebe a rebelarse contra el poder establecido ${ }^{7}$.

El charlatán más famoso fue un falso profeta oriental llamado Alejandro que se hizo millonario vendiendo unos oráculos que protegían supuestamente a los moradores de las casas contra la pestilencia, pero como dice Luciano de Samosata, "el verso era el siguiente: Febo, el de incortable cabellera, aleja una nube de peste. Y en todas partes se podía ver el verso grabado en los portales como fármaco para rechazar la epidemia. Pero para la mayoría de las casas, las cosas salían al revés. Con la suerte de espaldas, se quedaban vacías las casas en cuyo portal estaba grabado el verso" ${ }^{14}$. La superstición era la única manera que tenían los romanos de enfrentarse -sin éxito por lo demás- a la peste, al parecer.

\section{Conclusión}

El impacto de la peste fue importante para la población del Imperio Romano, se perdieron vidas humanas de manera trágica, pero sobre todo puso en jaque la llamada época de oro puesto que mientras la peste cobraba su punto álgido, el Imperio enfrentaba guerras en diferentes frentes. Claramente la peste terminó por alterar la pax romana asestando un crudo golpe a la paz y estabilidad lograda.

Nos referimos a esta como una peste de carácter global en dos sentidos. Un sentido geográfico ya que la desenvoltura de movimientos y los contactos de los diferentes grupos culturales facilitó la rápida difusión de la peste a lo largo y ancho del Imperio Romano. En segundo lugar porque los impactos de la pandemia fueron globales afectando la sociedad, el sistema de creencias religiosas, el ejército y la economía del Imperio Romano.

No hubo parte del Imperio Romano que de alguna manera no se viera afectada por la epidemia, las clases dirigentes se vieron trastocadas, los pobres morían, la mano de obra y los soldados escaseaban. La coyuntura fue crítica, no para una parte del mundo solamente, sino que para esa que se sentía dentro de una sociedad y territorio común.

En el siglo II no se disponía de la misma tecnología y avances médicos actuales, lo que explica claramente los efectos de la pandemia en todo el orbis romanus. Resulta, por lo tanto, lícito reflexionar qué posible reacción podría tener nuestra sociedad, que vive en una aldea global interconectada, frente a una coyuntura similar y el impacto que esto podría tener en la economía, política y sociedad mundial actual.

Agradecimientos: Agradezco al profesor Joel Parra Díaz de la Universidad de La Frontera, por la revisión y conversación respecto de esta nota histórica. Este artículo ha sido escrito en el marco del Proyecto de Iniciación de la Investigación: "La Pax Antonina: Estrategia, Geografía y Pensamiento Militar durante los Flavios y Antoninos. (70-192 AD)" DIUFRO DI15-0001, de la Universidad de La Frontera, del cual el autor es responsable y agradece la posibilidad de desarrollarlo.

\section{Resumen}

La peste Antonina fue la primera peste que afectó globalmente al mundo occidental. Perturbó todas las dimensiones de vida del género humano en el Imperio Romano tales como la economía, la política, la religión y la cultura. La literatura especializada menciona que la mortalidad alcanzó un $10 \%$ de la población. A su vez, la existencia del Imperio Romano con un fuerte carácter ecuménico desde el punto de vista cultural y territorial coadyuvó a la rápida propagación de la peste, como podría ocurrir en nuestra sociedad actual ante una pandemia similar. En conclusión, se sostiene que la epidemia fue global tanto en un sentido de la extensión geográfica como en los efectos que ésta tuvo en la población.

\section{Referencias bibliográficas}

1. Gibbon A. The decline and fall of the Roman Empire. Wordsworth Editions, $1^{\text {th }}$ Edition, Hearthfordshire 1998.

2. Birley A. Marco Aurelio: Una biografía. Editorial Gredos, $1^{\mathrm{a}}$ edición, Madrid, 2009.

3. Woolf G. Becoming Roman: The origins of provincial civilization in Gaul.Cambridge Universitary Press, $1^{\text {th }}$ Edition, Cambridge 2003.

4. Bancalari A. Orden Romano e Imperio Global, la romanización de Augusto a Caracalla. Editorial

Universitaria, $1^{\text {era }}$ Edición, Santiago de Chile, 2007.

5. Roberts J. Oxford dictionary of the classical World. Oxford University Press, Oxford 2007.

6. Cascón A, Picón V. Historia Augusta. Akal, $1^{\text {era }}$ Edición, Madrid 1989.

7. Fraschetti A. Marco Aurelio: La miseria de la filosofía. Marcial Pons Editores, $1^{\text {era }}$ edición, Madrid 2014.

8. Carcopino J. La vida cotidiana en Roma en el auge del Imperio. Ediciones Temas de Hoy, $1^{\text {era }}$ Edición, Madrid 2001.

9. Marcelino A. Historias. Akal, $1^{\text {era }}$ Edición, Madrid 2002.

10. Cunha C B, Cunha B A. The great plagues of the past: remaining questions. En: M. Drancourt, D. Raoult Eds. Paleomicrobiology: past human infections. Elsevier, New York; 2007: 1-20.

11. Littman R J, Littman M L. Galen and the Antonine plague. American J Philol 1973; 94: 243-55.

12. García del Corral I. Cuerpo del Derecho Civil Romano. Jaime Molinas Editor, Barcelona 1883.

13. Silver M. Antonine plague and deactivation of spanish mines. Arctos, Acta Philologica Fennica 2011; 45: 133-142.

14. De Samosata L. Alejandro o el falso profeta. Gredos, $1^{\text {era }}$ Edición, Madrid 1988. 